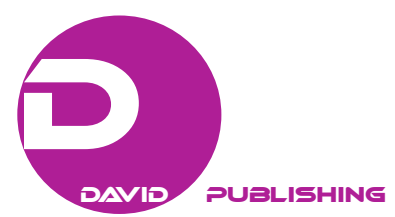

\title{
Refining Industry Development Trends in Azerbaijan
}

\author{
Saadet Mamedamin Asgar-Zadeh, Olga Borisovna Urban, Mansura Nizam Javadova, \\ İlhama Anver Khudieva, Sabina Huseyn Eldarova, \\ Emil Aydin Alkhasli, Niyazi Alasgar Mammadov \\ Institute of Petrochemical Processes ANAS, Baku, Azerbaijan
}

\begin{abstract}
On the basis of the analysis of development trends in the global refinery, the results of research to improve the effectiveness of the oil refining industry in Azerbaijan have been presented. Variants of complex schemes of oil refining have been considered, which take into account specialty of Azerbaijani oil and future requirements for the quality of processed oil products and which provide for the development of oil refining synchronously with the development of related industries (oil and gas production, petrochemistry, and power generation). In line with trends of the development of global refining, it identified advantages of integrated processes-refining-petrochemistry and oil and gas processing-petrochemistry, within a single fuel and energy complex. Based on calculations, the maximum profitability of a refinery is $17 \%$, while in refining-petrochemistry integration scenario, it rises to $25 \%$ and $35 \%$, if gas processing is integrated with refining and petrochemistry.
\end{abstract}

Keywords: oil and gas processing complex, integrated processing schemes, oil processing efficiency, integration of oil refining, petrochemistry and gas processing, profitability

\section{Oil Refining in Azerbaijan}

The oil refining industry in the Republic of Azerbaijan has a history of more than a century. As the industry developed, the low capacity refineries improved their structures and consolidation of plants took place. As a result, Azerbaijan now possesses a large fuel and lube refinery with a well-developed infrastructure. The high quality of Azerbaijani crudes used as basic feedstock in domestic refining industry ensures production of high-quality fuels and lubes.

This is a sure sign of the fact that Azerbaijan, while remaining a fairly large crude oil exporter, is also a potentially powerful producer of petroleum products for both domestic market and neighboring countries (Turkey, Iran, Russia, Georgia, etc.). Moreover, the balanced development of domestic oil refining industry is possible in the framework of a unified concept of development, to the development of which presented studies are devoted.

Saadet Mamedamin Asgar-Zadeh, Ph.D., Institute of Petrochemical Processes, Baku, Azerbaijan. Olga Borisovna Urban, master's degree, Institute of Petrochemical Processes, Baku, Azerbaijan. Mansura Nizam Javadova, Ph.D., Institute of Petrochemical Processes, Baku, Azerbaijan.

İlhama Anver Khudieva, graduate student, Institute of Petrochemical Processes, Baku, Azerbaijan.

Sabina Huseyn Eldarova, graduate student, Institute of Petrochemical Processes, Baku, Azerbaijan.

Emil Aydin Alkhasli, graduate student, Institute of Petrochemical Processes, Baku, Azerbaijan.

Niyazi Alasgar Mammadov, bachelor's degree, Institute of Petrochemical Processes, Baku, Azerbaijan.

Correspondence concerning this article should be addressed to Saadet Mamedamin Asgar-Zadeh, 30, Khojaly avenue, Baku, Az1025, Azerbaijan. E-mail: askerzade.saadet@gmail.com. 


\section{Prospects of Development of Oil Refining}

The development challenges and prospects of the domestic oil refining are inextricably linked to the global refining trends. The analysis of development trends of the world's major oil companies has demonstrated that a refinery should elaborate a long-term development strategy to comply with technical and environmental requirements and to be prepared to deliver products to the international market; that strategy may be adjusted as market situation changes.

Such strategy developed in the Republic of Azerbaijan under the supervision of Heydar Aliyev has been successfully implemented. The strategy builds upon the increasing efficiency of the oil industry. It stipulates the gradual replacement (diversification) of crude export with export of high added value petroleum products. Moreover, the primary objective of the national petroleum complex is narrowed down to the structural reorganization in the refining and gas processing industries, which in turn calls for resolving the top issue: revamping technical facilities and setting up the regulatory framework.

The Institute of Petrochemical Processes of the Azerbaijan National Academy of Sciences has for many years conducted researches dedicated to developing such integrated crude processing strategy that would boost the efficiency of national refining industry. These researches are targeted to set up the basis for the complex development of the national refining industry. These studies are based on wide-scale innovations and investments that are necessary for profound modernization of the industry and development of the domestic market and come down to increase of crude conversion rate, improvement of petroleum product quality, and integration with petrochemicals.

\section{Assigned Tasks}

The intensification of production issue is related to solving technical and environmental problems of the industry, as well as to the higher extent, the economic problems. Therefore, the objective was set to develop a comprehensive solution for such technical, environmental, and economic problems. Integrated refining schemes have been developed with: consideration for the global refining industry development trends, features of Azerbaijani crudes, energy and petrochemical infrastructure, internal petroleum demand, and export capabilities; prospective requirements for products with an account of environmental and economic imperatives on which a facility and market operates. Development of integrated schemes and their technical and economic assessment was carried out in accordance with the methodology adopted for enterprises of oil refining and petrochemical industries. The price of crude and products was made on the basis of average world data (Rustamov \& Asgar-Zadeh, 2008; Asgar-Zadeh, 2005; Braginsky, 2009; Bushuyev et al., 2010; Asgar-Zadeh, Khydyrov, Urban, Javadova, \& Eldarova, 2009; Rustamov et al., 2011).

\section{Ways of Solving Tasks}

In the development of fuel production scheme of oil refining, the introduction of solvent deasphalting (SDA), fluid-catalytic cracking (FCC), hydrocracking (HC), and delayed coking (DCU) has been provided that help increase the conversion rate to $90 \%-95 \%$ and upgrade the finished petroleum stock (up to euro- 4 and euro-5).

To ensure the flexible gasoline production scheme, a balanced variant has been anticipated between gasoline (US) and diesel (Western Europe) oriented configurations. This is achieved by adjusting the load of FCC and $\mathrm{HCU}$, which will enable (depending on the market situation) to ramp up the gasoline and diesel production. Utilized here is the global state-of-the-art technology and institute of petrochemical processes' developments 
aimed at reducing aromatics and benzene in gasoline, hydrotreating diesel and jet fuels, and processing FCC gases into high-octane oxygen-containing compounds; furthermore, a petrochemical version of catalytic cracking has been foreseen that enables to double the olefin-containing fraction output (Figure 1). The priority global technology will enable to produce gasoline with benzene content of $0.2 \%$, aromatics up to $10 \%$, and sulfur up to $10 \mathrm{ppm}$ (both in gasoline and diesel). The high quality of petroleum products will ensure stable sales and payback. Technoeconomic studies have shown that, considering the domestic market and national export capabilities, the payback time is going to be four to five years, or two to half and two years with partial export sales.

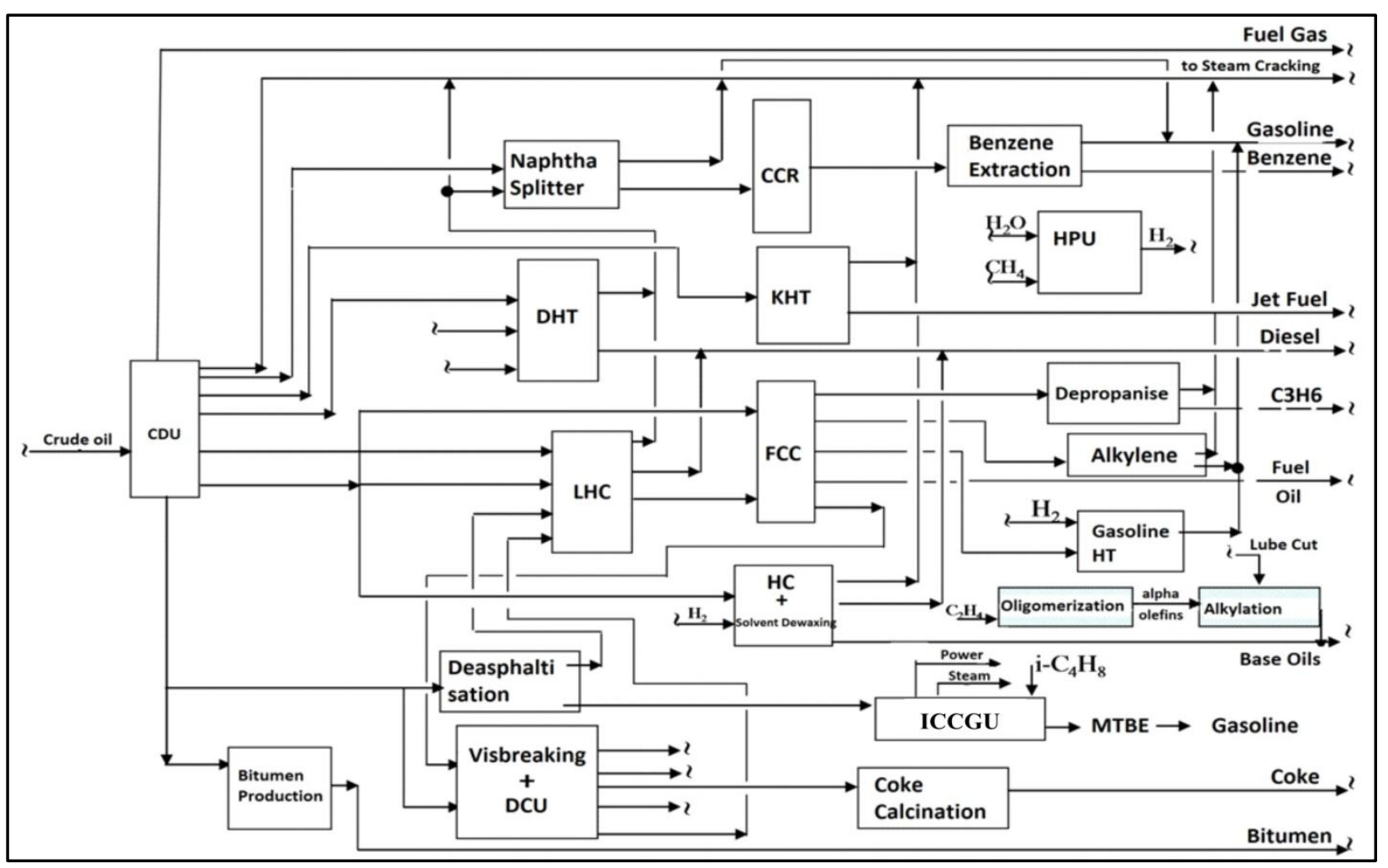

Figure 1. Oil refinery-petrochemical case.

Alongside separate conversion of unique crudes and conventional lube production chain, introduction of new conversion increasing capacities (solvent deasphalting and HC) has been anticipated as well as of those to upgrade the base oil quality through changing the lube fraction structure by $\mathrm{HC}$ and alkylation with alpha-olefins.

In the distant future, it is anticipated to implement an integrated combined-cycle gasification unit (ICCGU) that will enable to process heavy oil residue into $\mathrm{CO}$ и $\mathrm{H}_{2}$ used to produce methanol and high-octane gasoline components, as well as to resolve the system power supply issue, thus securing operational dependability and stability of the overall complex (facility).

Considering advantages of crude conversion to finished petrochemical stock offers, several options of complex petrochemical schemes have been developed. In doing so, both directions that the global petrochemical industry has gone have been studied:

- independently at petrochemical facilities, with studying the issue of supplying feedstock to steam crackers, that is gases (natural and associated) and naphtha from a refinery and olefin-consuming facility schemes (ethylene, propylene, and butylene) that convert olefins into polymers and rubbers; 
- directly at a refinery through integration between refining and petrochemical production.

The refining/gas processing/petrochemical complex that has been suggested incorporates facilities that recover benzene from liquid SC products and convert $\mathrm{SC} \mathrm{C}_{4}$ into butadiene and polybutadiene (Figure 2). From ethylene authors can produce polyethylene and alpha-olefins that are further used in production of synthetic detergents and semi-synthetic lubes; propylene gives polypropylene.
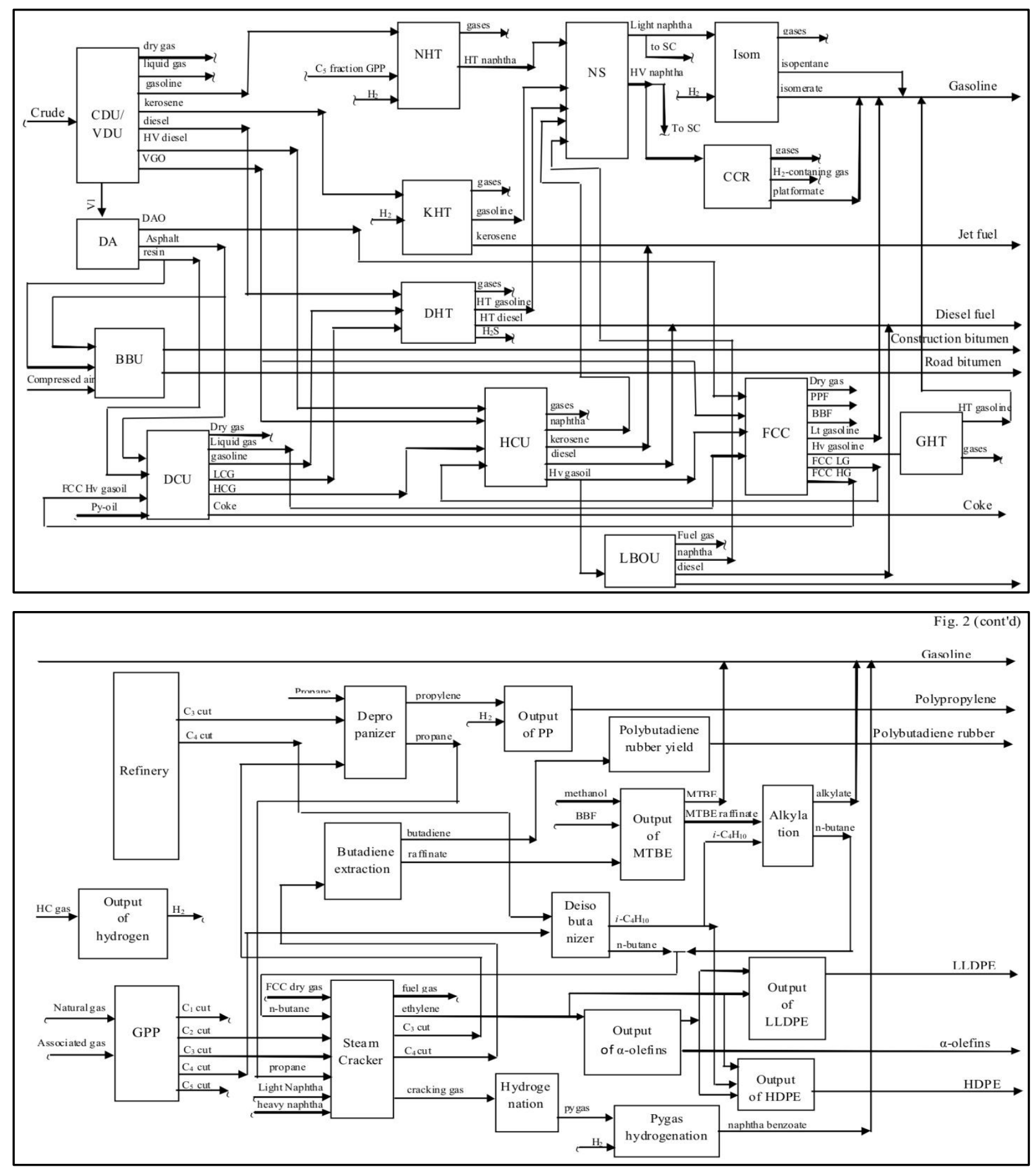

Figure 2. Refining + gas processing + petrochemical complex. 


\section{Capabilities of Integration}

The integration gives positive effect due to combining production facilities, activating streams, and utilizing infrastructure and feedstock for petrochemical units at a low cost. The combination effect, economy of scale, and cheap feedstock render the products competitive and highly demanded in the market. The integration efficiency is especially noticed, when oil prices hit the bottom. Since the petrochemical and chemical product price is, as a rule, falling down slower than that of crude and petroleum products, and some products even do not get cheaper at all, the oil companies manage to partially offset the oil-related losses by selling petrochemicals.

Therefore, on one hand, the pyrolysis unit efficiency increase and effective feedstock supply shall be attained through integration of refining, gas processing, and petrochemical facilities. On the other hand, integration with petrochemicals boosts the efficiency of the very oil refining. For the sake of example, the gasoline quality can be improved by means of diisopropyl ether which is produced at isopropanol units of petrochemical facility or high-index semi-synthetic lubes, by alkylation of lube fractions with alpha-olefins, as well as by implementing HCU within the facility.

\section{Results of the Preliminary Technical and Economic Calculations}

The technical and economic analysis has shown that such project could be feasible, if HC products would be used as a feedstock for SC or to produce highly viscous lubes (VI > 120). Thus, the key parameters in synergy-boosting integration of refining and petrochemical processes are the increase of hydrocracker efficiency through rational utilization of its by-products on one hand and increase of SC loading on the other. Implementing both options at the same time, authors can optimize HC process in terms of price and capacity of both steam cracker and lube base oil unit. The increasingly stringent requirements for product quality call for additional conversion using costly hydrogenation processes (high pressure/temperature), new catalysts, and process systems. Naturally, this results in increased refining cost and does not always solve the problem. In order to make the production of environmentally friendly petroleum products at constant market prices for oil and products profitable for the producer, authors made the technoeconomic assessment of each individual process and the facility as whole when developing the complex schemes. First and foremost, the investments required to make high-quality petroleum and the payback time has been identified. The technoeconomic analyses of complex schemes performed in six different options have established that the plant integration and modernization of conversion scheme help cut down operating costs, while the margin jumps two to three times compared to crude refining split by refineries and petrochemical facilities. The payback time here is less than three years. The refining efficiency boost was attained by processing by-products, at petrochemical facilities among all.

Therefore, the third course of refining intensification has been followed: integration with petrochemicals, which makes it possible to react swiftly to changing market situations and turn losses into gains: Calculations show that refining margin for the petrochemical option is 1.8 times than that of the refining option (41 USD/ton against $23 \mathrm{USD} /$ ton).

The study made on the premises of refining 10 MTA of crude and processing 10 BCMA of gas established that the maximum IRR of a refinery is $17 \%$, while in refining-petrochemicals integration scenario, it reaches $25 \%$ and $35 \%$, if gas processing is integrated with refining and petrochemicals. 


\section{Conclusions}

Therefore, the development of fuel and energy complex that overlies the four production sectors shall be defined by a balanced combination of adjacent industries, whose development is to reinforce the very overall fuel and energy complex. The principal link in this particular chain is refining. It should be said in conclusion that it is the high quality of Azerbaijani crudes as well as available technical basis, well-developed infrastructure, and the scientific and human capacity that gives the country the grounds to increase the domestic refining efficiency.

\section{References}

Asgar-Zadeh, S. M. (2005). Concerning refining intensification. Refining and Petrochemical Processes, 1(20), 82-89.

Asgar-Zadeh, S. M., Khydyrov, B. S., Urban, O. B., Javadova, M. N., \& Eldarova, S. H. (2009). Power supply of refineries in Azerbaijan. Chemistry and Technology of Fuels and Oils, 5, 16-19.

Braginsky, O. (2009). Petrochemical complex of the world. Moscow: Academia.

Bushuyev, V. V., Kryukov, V. A., Sayenko, V. V., Silkin, V. U., Tokarev, A. N., Shaphranik, U. K., \& Shmatt, V. V. (2010). Russian oil industry - Balanced development scenario. Moscow: Institute of Energy Strategy.

Rustamov, M. I., Asgar-Zadeh, S. M., Urban, O. B., Javadova, M. N., Eldarova, S. H., \& Ismayilova, G. T. (2011). Integration of refining facilities. Chemical Engineering, 7, 16-19.

Rustamov, M. I., \& Asgar-Zadeh, S. M. (2008). Prospects of development of the oil refining industry in Azerbaijan. Azerbaijan Oil Industry, 14, 7-14. 